\title{
An appraisal of incentives for developing green hotel buildings
}

\author{
P. Sloan, W. Legrand, C. S. Kaufmann \& M. Belz \\ ${ }^{I}$ International University of Applied Sciences, Bad Honnef, Germany
}

\begin{abstract}
In 2007 the UNWTO forecasted a doubling of international arrivals by the mid 2000s [1]. This coincides with ever increasing pressure from across society for the tourism and hospitality industries to present a more sustainable future. Since nearly all tourism arrivals include overnight stays, the first line of attack by the hospitality industry in the fight against excessive use of expensive fossil fuels is making buildings more energy efficient. Depending on the climate, the costs for energy on average represent $30-35 \%$ of a hotel's operating costs [2]. This study aims to identify those incentives for German hoteliers that make building, renovating, or expanding hotels in an energy efficient manner attractive and conversely to uncover reasons that hinder this trend. According to the Building Design \& Construction [3] study $65 \%$ of hoteliers have already incorporated sustainable concepts into recent hotel building or renovation work citing guests' expectations as the major motivation factor. The result is comparable to the findings of this study where more than half of the respondents give the same reason for this type of investment. Nearly $90 \%$ of the study population regards the construction of a green hotel as more than $11 \%$ costlier than a conventional building. This is astonishing because different investigations have shown that the costs of green buildings do not exceed more than $10 \%$ of initial construction costs. Compared to conventional buildings the medium cost increase of LEED certified buildings is about $1.6 \%$ [4]. The second biggest obstacle is the lack of financial incentives and state subsidies (49.6\%). In conclusion, energy efficient and environmentally friendly hotel real estate investments are only of interest to most hoteliers, at the present time, when subsidies are available.
\end{abstract}

Keywords: energy efficient building, German hospitality industry, incentives and hindrances. 


\section{Introduction}

The great environmental challenges of our time are to reduce mankind's dependence on fossil fuels, develop new energy sources and reduce carbon dioxide emissions. Despite the economic crisis, global energy demand is set to double by 2050 and possibly by 2030 . During this period world population will increase from currently 6.5 billion people to about 9 billion people [5]. Additionally, in the near future the world reserves of non-renewable energies might not be able to cover the demand. At the moment, coal, gas, and oil cover around $80 \%$ of the worldwide energy demand, and are responsible for most of the carbon dioxide emissions and other greenhouse gases that are heating up the planet. Therefore, renewable energies such as solar energy, wind and biomass fuels have to cover the demand in the future [6].

According to the UNEP, the travel and tourism industries presently generate already 5 per cent of global $\mathrm{CO}_{2}$ emissions [7]. Current forecasts predict that "in less than thirty years if no action is taken today, $\mathrm{CO}_{2}$ emissions generated by tourism will be more than three times higher than today" [8]. While the accommodation sector is one of the tourism industry's largest economic drivers, it is also one of the most energy-intensive parts of the industry, responsible for 21 per cent of total $\mathrm{CO}_{2}$ emissions in global tourism [9]. Accordingly "among the greatest polluters and resource consumers within the service industries" [10] the whole value chain and life cycle of hospitality operations should be reviewed in order to minimize negative impacts on surrounding ecosystems.

As the international tourism market continues to grow, it will have a major impact on the environment and thus responsible for climate change. Baker [11] has reported that the WTO "forecasts that internationals tourism arrivals are expected to reach over 1.56 billion by the year 2020 compared with a figure of 760 million in 2004. Of the 2020 arrivals, 1.18 billion are forecast to be intraregional and 277 million will be long-haul travellers. At some point on their journey, most of them will need somewhere to stay" [12]. Hence, the hospitality Industry has an intrinsic link to the building industry. According to the United States Energy Information Administration (EIA) buildings are responsible for nearly half (48\%) of total energy consumption and greenhouse gas emissions annually [13]. $76 \%$ of all electricity generated by U.S. power plants goes to supply the Building Sector [14]. Thus, the building sector as the main contributor to climate-changing toxic substances has got a high potential to reduce worldwide greenhouse gas emissions [15].

According to the WBSCD study 'Energy Efficiency in Buildings', 40\% of global energy consumption and thus environmental pollution is caused by worldwide energy-use of buildings [16]. This demonstrates how huge the potential is to save energy that incidentally reduces environmental pollution and is in line with the UN targets to reduce global warming. According to the International Tourism Partnership (ITP) environmental responsibility for hotels begins with the design and construction process of real-estate development.

This study aims to identify those incentives for German hoteliers that make building, renovating, or expanding hotels in an energy efficient manner 
attractive. Conversely, the study also aims to uncover reasons that hinder this trend. An Industry wide survey was conducted covering a variety of 145 privately owned hotels and chain hotels. In $71 \%$ of hotels questioned, it was the owner that answered the online questionnaire.

\section{Literature review}

The building industry has the largest potential for delivering long-term, significant and cost-effective greenhouse gas emission reductions including $\mathrm{CO}_{2}$. With proven and commercially available technologies, the energy consumption in both new and existing buildings can be cut by an estimated 30 to 80 percent during the life-span of a building [17]. Buildings have a relatively long life, therefore, action taken continue to affect their greenhouse gas emissions over many years. Energy "is essential for heating, cooling, lighting and circulating water around buildings and for ensuring a comfortable internal environment" [18]. Nevertheless, energy generation and consumption have huge environmental impacts and financial costs. In 1970, a barrel of crude oil cost 3 US dollars. Since this time there has been a rapid increase in cost of oil. A record was reached in 2008 when a barrel of crude oil reached the price in world markets of 146 US Dollars [19]. The price for natural gas is strongly connected to the price of crude oil. In addition, prices for electricity increased by nearly $40 \%$ in Germany between 2000 and 2009 [20]. Depending on the climate, the costs for energy on average represent $30-35 \%$ of a hotel's operating costs. Energy efficiency techniques for hospitality operations as well as renewable energy usage are one way to respond since high energy consumption and associated costs in hotels is a huge problem within this industry and are beginning to find their place in some properties [21].

Buildings are considered sustainable (green) if "they are designed, built and operated with low environmental impacts (or, in some cases with positive environmental impacts) while enhancing the health, welfare and quality of life of the people that live and work in them" [22]. Green or eco-architecture provides design in harmony with nature, including its immediate environment.

Furthermore, green buildings have less negative impact on the environment and they also yield a greater return on investment [23]. The International Council for Research and Innovation in Building and Construction defined sustainable construction as "creating and operating a healthy built environment based on resource efficiency and ecological design" [24] and developed seven Principles of Sustainable Construction [25], as shown in Table 1.

Research conducted by the University of Stuttgart and PE International $\mathrm{GmbH}$ to the topic of sustainable construction in Germany is of interest to different groups, institutions and organizations. Thereby diverse motivations, objectives and backgrounds play an important role. Experience and research have shown that buildings that are built under consideration of sustainability criteria have several advantages compared to conventional real-estate [26]. The most important benefits are shown as shown in Table 2 . 
Table 1: $\quad$ The seven principles of sustainable construction.

\begin{tabular}{|ll|}
\hline 1. & Reduce resource consumption \\
\hline 2. & Reuse resources \\
\hline 3. & Use recyclable resources \\
\hline 4. & Protect nature \\
\hline 5. & Eliminate toxics \\
\hline 6. & Apply life-cycle costing \\
\hline 7. & Focus on quality \\
\hline
\end{tabular}

Table 2: $\quad$ Sustainable building advantages [27].

\begin{tabular}{|l|}
\hline Lower life cycle costs and insurance premium \\
\hline Increased market value of the property and higher productivity \\
\hline Improved image \\
\hline Reduced risks \\
\hline Positive influence on health of residents \\
\hline Reduced effects on infrastructure, environment and local economy \\
\hline
\end{tabular}

In 2007, the Building Design+Construction $(\mathrm{BD}+\mathrm{C})$ and Hotels magazine conducted a survey asking around 5000 hoteliers on their level of interest, knowledge and proceedings regarding green buildings and sustainable management practices within their organizations. According to this US study the "overwhelming majority (88\%) of survey respondents said that they were somewhat of very familiar with green building, and an equally high percentage $(80 \%)$ said that they had a medium to high level of interest in green building and sustainable design" [28].

The hospitality industry "has been waiting for increased consumer demand and lower costs before it fully embraces green operations" [29]. According to Butler [30] current studies have shown that the costs for developing a green building are neutral or even insignificant. In more detail, he states that "current studies show that the cost of building to LEED standards is not greater than conventional approaches, while those buildings are healthier for occupants and less expensive to operate" [31].

Certain green innovations that lead to higher energy efficiency provide tax breaks for developers, users and owners of the property. In addition, it also has to be considered that the additional initial construction costs for energy efficient technologies will result in an increased return on investment especially due to savings in energy costs [32]. An USGBC study found out that "energy savings for green buildings ranged from 25 to 30 percent, with an average of 28 percent [33].

\subsection{Two best-practice examples}

In order to obtain a clearer understanding on how to build and operate environmentally friendly hotels two hotels are presented that have successfully 
incorporated sustainable construction measures. Both hotels are privately owned and after renovation became a zero-environmental-emission buildings.

\subsubsection{Best Western Hotel Victoria in Freiburg, Germany}

Since 2006, the Best Western Hotel Victoria in Freiburg, Germany has successfully operated in coherence with the European Eco-management and Audit Scheme (EMAS) with a very low energy use balance [34]. Thus, it is one of the few hotels worldwide with a zero-emission standard making it "the most environmentally friendly private-hotel in the world" [35]. According to the hotel's environmental statement the property "supplies itself with emission-free power and is therefore considered a zero emission hotel" [36] referring to the nearly zero rate of harmful greenhouse gas carbon dioxide emitted by the hotel. The hotel owner, Mr. Später claims that by using intelligent, state-of-the-art technology combined with environmentally friendly and sustainable management his hotel is able to achieve environmental protection and healthy profitability [37].

\subsubsection{Hotel Stadthalle in Vienna, Austria}

Environmental awareness and sustainable operations are the main focus of the Hotel Stadthalle in Vienna, Austria. In November 2009 the hotel opened its new wing in line with a passive energy use standards and a zero energy balance. This means that the hotel makes its own energy requirements through a combination of renewable energy technology; a ground-water pump, a photovoltaic power plant, solar energy plant, and three wind turbines on the roof [38]. The entire heating and cooling system for this passive building, hotel is acquired through a water-heat-pump. In addition, the entire system is equipped with an essential residential-property-ventilation system that minimizes humidity. The system is supported by the solar energy plant with its $130 \mathrm{~m}^{2}$ solar panels. The environmental awareness of the Hotel Stadthalle is expressed by promoting ecofriendly and sustainable management practices at operational level, all employees are trained to take environmental responsibility [39].

\section{Methodology}

An internet-mediated questionnaire as part of a survey strategy was adopted to collect quantitative data for the primary research purpose. In order to achieve the overall aim of identifying restrictive factors that constrain the development and use of sustainable and energy efficient construction measures in German hospitality industry, the questionnaire was sent out to members of the German Hotel and Catering Association (Deutscher Hotel- und Gaststättenverband, DEHOGA). The sampling frame consisted of 4,867 hotels and guesthouses. From these 145 valid responses were received, giving an overall response rate of around 3 per cent. The choice of a self-administered questionnaire was largely based on the desire to maximise the geographic coverage without an increase in costs. The questionnaire was developed and administered using the German language. The questionnaire was developed with questions based on motivations 
to implement sustainable construction, actual and planned investment behaviour, as well as general questions regarding characteristics of the hotel such as categorization, size of hotel and hotel equipment. In addition to discovering errors in questions, question sequencing or instructions, the pre-test was conducted to assess validity and reliability. The questionnaire was tested by a group of 8 industry and academic professionals in the field of architecture and hospitality management. Slight modifications pertaining to linguistics in the questionnaire were consequently performed to ensure the proper understanding of the questions.

\section{Findings}

The findings are analysed in three sections: (1) demographic profile of respondents, (2) motivations for investment, (3) cost of investment, (4) importance of sustainability factors in building and construction, (5) barriers to green technologies, (6) planned investments and (7) certification schemes adopted.

\subsection{Demographic profile of respondents}

A large majority of the questionnaires were answered by the owners of the hospitality operations ( $71 \%$ of all questionnaires). The proportion of private hotels $(91.7 \%)$ is higher than chain hotels $(8.3 \%)$. Regarding the categories of the hotels, the largest group are middle class hotels $\left(3^{*}\right)(67.8 \%)$, followed by luxury hotels $\left(4^{*}-5^{*}\right)(19.6 \%)$ and the minority is composed of budget hotels $(1 *-2 *)(12.6 \%)$. On average the guest ratio in the surveyed hotels is distributed by $47.08 \%$ business guests and $52.92 \%$ leisure guests. The average hotel has 46 rooms (mean $=45.57$ ), including the smallest hotel having 5 rooms and the largest one having 428 rooms. The average occupancy percentage of is $55.2 \%$, in 2009 , the average room rate of all the surveyed hotels was $68.11 €$.

\subsection{Motivations for investment}

Respondents said that the reason for investment is the extension of building capacity (rooms and restaurant) (17.3\%), followed by environmental and resource-saving aspects (15\%), achieving certifications for the building and operation $(12.1 \%)$, and financial incentives and subsidies (11.5\%). In a minority of cases $(6.8 \%)$ rotational replacement was the main reason for investment in renovation, rebuilding, or expansion of the hotel real-estate.

\subsection{Cost for investment}

According to the survey $11.3 \%$ of hoteliers assume that the cost difference between a green hotel and a conventionally constructed hotel is somewhat between no additional costs and up to $10 \%$ additional initial costs. $21.1 \%$ of respondents assume initial investment costs for a green hotel to be between $11 \%$ and $15 \%$, followed by the majority of respondents $(26.8 \%)$ assuming that a green 
hotel will be $16 \%$ to $20 \%$ more expensive regarding the initial construction costs. For $18.3 \%$ of hoteliers green buildings cost $21 \%$ to $25 \%$ more and nearly the same proportion of hoteliers $(22.5 \%)$ assume that green construction is more than $25 \%$ costlier compared to conventional buildings. These results are in line with earlier surveys supporting the presumption that the majority of German hoteliers perceive initial investment costs for green buildings compared to conventional buildings as highly expensive.

\subsection{Sustainability factors in building and construction}

$70.8 \%$ hoteliers consider environmental aspects like primary energy demand, water quality and sewage disposal as being very important. Nearly $60 \%$ of the hoteliers $(58.5 \%)$ believe the quality of the building project design and the quality of the construction to be of paramount importance. Further, the technical quality is of high importance to $55.2 \%$ of respondents such as fire protection, noise protection, and building insulation. The same proportion of hoteliers $(53.1 \%)$ said that the quality of the location of their hotel building including transport connections is of high significance. Finally, building in life-cycle costs are very important to only one third of respondents $(26.1 \%)$, whereas $57.7 \%$ of hoteliers said that this aspect is "important". None of the sustainability aspects are rated as unimportant and/or very unimportant by the majority of hoteliers. Thus, it can be said that sustainability aspects are of above-average importance to nearly all hoteliers.

\subsection{Barriers to green technologies}

The main barrier to accepting green technologies are the perceived significant initial construction costs for the majority of respondents $(61.9 \%)$. The second set of biggest obstacles is scarce financial incentives and state-run subsidies $(49.6 \%)$. Therefore, environmentally friendly investments and energy efficient building measures only become of interest to hotel keepers if financial incentives and state-run subsidies for sustainable building measures are available.

\subsection{Planned investments}

However, in the research survey, the majority of respondents $(75.2 \%)$ have already realised and/or will realise energy efficient building measures in the near future, for instance solar plant, photovoltaic, wood pellet heating, and insulation of the roof or the hotel frontage. The remaining hoteliers $(24.8 \%)$ do not have any plans to realise energy efficient building measures. Besides passive house technology wood pellet heating systems exist in $11.5 \%$ of the hotels questioned. The findings reveal that $61.1 \%$ of budget hotels and $78.6 \%$ of luxury hotels have already realized and or planned for 2010 to put sustainable building measures into practice. 


\section{Discussion}

Analysis highlights the reasons behind the investment behaviour: protecting the environment is more a reason for investment than long-term cost savings. Additionally, protection of the environment when investing in green architecture is of higher importance than profitability. Therefore, the major motivation for hoteliers to invest in the hotel property is primarily to protect the environment rather than to save money in the long-term with efficient technology. According to the Hotel Industry (2007) study [40] 65\% of hoteliers already have incorporated sustainable concepts into recent hotel building or renovation work citing guests expectations as the major motivation factor. The result is comparable to the findings of this study where more than half of the respondents $(53.5 \%)$ give the same reason for this type of investment. However, compared to the findings of the Hotelinvest studies of 2009 and 2010 that conclude a depressing economical situation in Germany and a morose investment climate are slowing down hotel building investment the findings of this survey are quite positive [41]. This research shows that around $70 \%$ of respondents are planning to invest more in 2010; the Hotelinvest study in 2010 [42] discovered only $40 \%$ $(25 \%)$. The reason for this may be that the actual Hotelinvest study collected the data in November 2009, whereas for this study the data was collected in March 2010. In Germany, on January 1st, 2010 the new value-added tax (VAT) for the hospitality industry came into force, reducing the VAT from formerly $19 \%$ to only $7 \%$ [43]. This tax shelter might have resulted in the increased investment behaviour identified in this study.

\section{Conclusion}

Rising energy costs, escalating operating costs, greater environmental awareness across society and evolving consumer preferences lead hoteliers to uncover new ways to gain a competitive edge in a huge global industry. Progressively minded hoteliers are looking towards green architectural design to attract a new generation of consumers and exploit an array of technologies that use renewable energy sources. As the availability of fossil fuels such as oil, coal and gas decline new renewable energy sources are emerging as replacements that do not carry the burden of an indelible carbon footprint. Already, examples of zeroenergy, zero-polution hotels exist, be they few and far between. This study shows that many German hoteliers have a growing awareness of environmental degradation and some are willing to invest in technology that will buck this downward spiral. However, many still believe that investment in green architectural initiatives and renovations will prove more costly than quick fix solutions even though sustainable technologies would be financially viable according to studies completed by McKinsey and national building accreditation organizations such as LEED and BREEAM. Since the potential to decrease energy use and carbon emissions in all industries is largest in the building sector it is reasonable to assume that green architectural design in hotel operations will 
increase in the near future as society realizes that it cannot go on degrading the eco-systems and resources of this planet indefinitely.

\section{Recommendations and further research}

Since this study was only conducted in three German states, a more general comparison of the findings to other German states and to other countries should be made. Additionally, it would be interesting to analyze this subject with a qualitative research approach.

Certifications for sustainable buildings should be developed internationally and specifically for the hospitality industry. Green building terminology is not internationally agreed upon and should be regulated by law. Thus, generally accepted definitions are needed and should be developed soon. Since initial construction costs are the main barrier for hoteliers to implementing sustainable construction measures more case studies highlighting individual solutions should be developed. Here, two project types should be analyzed: initial construction costs for renovation of existing hotel buildings vs. initial construction costs for newly build hotels. Finally, low-interest investment facilities should be created for hoteliers in addition to attractive governmental subsidies in order to stimulate green architectural initiatives.

\section{References}

[1] UNWTO (2008). World Tourism Barometer. Retrieved June 19, 2010 from http://www.tourismroi.com/Content_Attachments/27670/File_6335137500 35785076.pdf

[2] Building Design \& Construction (BDC). Hotel Industry Slowly Overcomes Reservations about Green Building, p. 46, 2007.

[3] Building. Green construction not as expensive, 2008. www.building.co.uk/sustain_story.asp? sectioncode $=747 \&$ storycode $=31282$ 09\&channel=747\&c=3\#ixzz0iH5M0h7E

[4] United Nations (UN), About the UN Commission on Sustainable Development (CSD), UN Department of Economic and Social Affairs Division for Sustainable 2009. www.un.org/esa/dsd/csd/csd_aboucsd.shtml

[5] United Nations Environment Programme (UNEP), United Nations Environment Programme: UNEP Milestones, 2003. www.unep.org/Documents.multilingual/Default.asp?DocumentID=287

[6] United Nations Environment Programme (UNEP), United Nations Environment Programme: UNEP Milestones, 2003. www.unep.org/Documents.multilingual/Default.asp?DocumentID=287

[7] United Nations Environment Programme (UNEP), Building Capacity on Climate Change and Tourism, International Task Force on Sustainable Tourism Development. www.unep.fr/scp/tourism/activities/taskforce/pdf/ fact $\% 20$ sheets $\% 20 \mathrm{pdf} /$-Climatechange.pdf 
[8] United Nations Environment Programme (UNEP), Building Capacity on Climate Change and Tourism, International Task Force on Sustainable Tourism Development, p.1. www.unep.fr/scp/tourism/activities/ taskforce/pdf/fact\%20sheets\%20pdf/-Climatechange.pdf

[9] United Nations Environment Programme (UNEP), Buildings and Climate Change: Status, Challenges and Opportunities, eds. P. Huovila, M. AlaJuusela, L. Melchert, and S. Pouffary, UNEP Sustainable Buildings and Climate Initiative, Paris. 2007

[10] Sloan, P., Legrand, W., \& Chen, J. S., Sustainability in the hospitality industry: Principles of Sustainable Operations, Butterworth-Heinemann: Oxford, p.6, 2009

[11] Baker, C., (ed.). Sustainable hotel - siting, design and construction, International Tourism Partnership; London, 2005.

[12] Baker, C., (ed.). Sustainable hotel - siting, design and construction, International Tourism Partnership; London, p. 8, 2005.

[13] Battles, S. J., \& Burns, E. M. Trends in Building-Related Energy and Carbon Emissions: Actual and Alternate Scenarios. United States Energy Information Administration Web site, Washington DC, 2000. www.eia.doe.gov/emeu/efficiency/aceee2000.html

[14] Architecture2030. How to stop global warming. www.architecture2030.org/ current_situation/stop_coal.html

[15] BRE., BREEAM and benefits of green buildings, 2009. www.bre.co.uk/webinar/breeam

[16] WBCSD., Transforming the market: energy efficiency in buildings, 2009. www.wbcsd.org/DocRoot/WvNIJhLQBmClKuj0eN0h/91719_EEBReport_ WB.pdf

[17] United Nations Environment Programme (UNEP), Buildings and Climate Change: Status, Challenges and Opportunities, eds. P. Huovila, M. AlaJuusela, L. Melchert, and S. Pouffary, UNEP Sustainable Buildings and Climate Initiative, Paris. 2007

[18] Baker, C., (ed.). Sustainable hotel - siting, design and construction, International Tourism Partnership; London, p.54, 2005.

[19] BBC News, Oil price hits yet another record. http \\news.bbc.co.uk/2/hi/business/7486764.stm

[20] Spiegel Online International, Skyrocketing Oil Prices Threaten Prosperity. www.spiegel.de/international/business/0,1518,556367,00.html

[21] U.S. Energy Information Administration (EIA), Independent Statistics and Analysis 2010. www.eia.doe.gov/

[22] Light House. What is a sustainable building?, para. 3, 2010. www.sustainablebuildingcentre.com/learn/what_is_a_sustainable_building

[23] Lockwood, C., Building the Green Way, Harvard Business Review, 84(6), pp. 129-137, 2006.

[24] cited in Kibert, C., Sustainable construction: green building design and delivery, John Wiley \& Sons, Inc: New Jersey, p. 6, 2008.

[25] data retrieved from Kibert, C., Sustainable construction: green building design and delivery, John Wiley \& Sons, Inc: New Jersey, p. 6, 2008. 
[26] Braune, A., Sedlbauer, K., Kittelberger, S., \& Kreissig, J., Potenziale des nachhaltigen Bauens in Deutschland: Analyse der internationalen Strukturen, Stuttgart, 2007.

[27] data retrieved from Braune, A., Sedlbauer, K., Kittelberger, S., \& Kreissig, J., Potenziale des nachhaltigen Bauens in Deutschland: Analyse der internationalen Strukturen, Stuttgart, 2007.

[28] Building Design \& Construction (BDC). Hotel Industry Slowly Overcomes Reservations about Green Building, p. 44, 2007.

[29] Butler, J., The Compelling Hard Case for Green Hotel Development. Cornell Hospitality Quarterly, 43(3), p. 237, 2008.

[30] Butler, J., The Compelling Hard Case for Green Hotel Development. Cornell Hospitality Quarterly, 43(3), pp. 234 - 244, 2008.

[31] Butler, J., The Compelling Hard Case for Green Hotel Development. Cornell Hospitality Quarterly, 43(3), p. 234, 2008.

[32] Business Travel News (BTN), Hoteliers Building Green Properties, 2007.

[33] U.S. Green Business Council (USGBC), What LEED Is. http://www.usgbc.org/DisplayPage.aspx?CMSPageID $=1988$

[34] Hotel Victoria, Umwelterklärung 2007, www.hotelvictoria.de/wsbk/ dokumente/Umwelt/Umwelterklaerung2007.pdf

[35] Hotel Victoria, Umwelterklärung 2007, www.hotelvictoria.de/wsbk/ dokumente/Umwelt/Umwelterklaerung2007.pdf

[36] Hotel Victoria, Umwelterklärung 2007, p. 3. www.hotelvictoria.de/ wsbk/dokumente/Umwelt/Umwelterklaerung2007.pdf

[37] Hotel Victoria, Umwelterklärung 2007, www.hotelvictoria.de/wsbk/ dokumente/Umwelt/Umwelterklaerung2007.pdf

[38] Reitterer, M., Hotel Stadthalle, 2009. www.hotelstadthalle.at/de

[39] Reitterer, M., Hotel Stadthalle, 2009. www.hotelstadthalle.at/de

[40] Building Design \& Construction (BDC). Hotel Industry Slowly Overcomes Reservations about Green Building, 2007.

[41] Allgemeine Hotel- und Gastronomie-Zeitung (AHGZ). Hotelinvest 2010: Investitionsverhalten der deutschen Hotellerie im Bereich 2- bis 4-Sterne, www.ahgz.de/themen/studien/hotelinvest.php

[42] Allgemeine Hotel- und Gastronomie-Zeitung (AHGZ). Hotelinvest 2010: Investitionsverhalten der deutschen Hotellerie im Bereich 2- bis 4-Sterne, www.ahgz.de/themen/studien/hotelinvest.php

[43] Allgemeine Hotel- und Gastronomie-Zeitung (AHGZ). Die Steuersenkung nutzt allen, 2010, www.ahgz.de/news/Die-Steuersenkung-nuetztallen,200012172732.html 